\title{
Does the premise of deep and surface approaches to learning still hold? A re-evaluation of the approaches to learning questionnaire
}

\author{
Alexander Whitelock-Wainwright \\ Portfolio of the DVC \& VP (Education), Monash University \\ Dragan Gašević \\ Faculty of Information Technology, Monash University \\ Trev Wood \\ Monash Education Innovation, Monash University \\ Kris Ryan \\ Portfolio of the DVC \& VP (Education), Monash University
}

\begin{abstract}
Author Note
Alexander Whitelock-Wainwright (D) https://orcid.org/0000-0003-3033-4629

Correspondence concerning this article should be addressed to Alexander

Whitelock-Wainwright, Portfolio of the DVC \& VP (Education), Monash University.

E-mail: alex.wainwright@monash.edu

Draft version 3, 27/07/2021. This paper has not been peer reviewed. Pleasedo not copy or cite without author's permission.
\end{abstract}




\begin{abstract}
Scores obtained from the Revised Two Factor Study Process Questionnaire (R-SPQ-2F) are regularly used in Higher Education to profile students as being Deep or Surface learners. Despite its utility, concerns about its validity have been mounting. Possible factor models have been tested - guided by the original theorising - yet consensus has not been achieved over what is a permissible representation. This study builds on this by seeking to answer a single research question of identifying the best factor model for the R-SPQ-2F. Using data collected from a final sample of 1,158 students, three models were tested using both Exploratory Structural Equation Modelling and Confirmatory Factor Analysis. Findings supported the original decomposition into four factors; however, this came at a cost of distorting factor definitions. A discussion of where these distortions arose and how they can be addressed is offered.
\end{abstract}

Keywords: Approaches to Learning, R-SPQ-2F, Factor Analysis 


\section{Does the premise of deep and surface approaches to learning still hold? A re-evaluation of the approaches to learning questionnaire}

\section{Introduction}

Education research regularly uses the Revised Two Factor Study Process Questionnaire (R-SPQ-2F; Biggs et al., 2001) to measure student attitudes towards study strategies and motivations. Examples include Ginns and Ellis (2007), who created learning profiles based on R-SPQ-2F scores, Bliuc et al. (2010), who explored the relationship between R-SPQ-2F scores and final grades, and Gašević et al. (2017) who explored the relationship between R-SPQ-2F scores and learning strategies obtained with analysis of digital trace data. The problem, however, is the growing number of studies raising concerns about the factor structure of the R-SPQ-2F (Justicia et al., 2008; Socha \& Sigler, 2014). This paper seeks to address such concerns by exploring various model representations offered in the literature.

\section{Approaches to Learning}

Biggs (1987) proposed the 3P (Presage, Process, Product) model of student learning that sought to capture the interplay of personal and situational factors in learning processes. Central to the $3 \mathrm{P}$ model is the learning process complex, which Biggs viewed as embodying the students' motives and strategies (Biggs, 1987). A motive is the reason the student approaches the task (e.g., to get a good grade). Strategy is the way the student approaches the task (e.g., making notes, reading widely, or rote learning).

Biggs posited that together, motives and strategies define three approaches to learning: Achieving, Deep, and Surface. Achieving Approaches are when students view learning as a competition, wherein the goal is to attain the highest grade. Deep Approaches are when students want to be competent in a subject because of an intrinsic interest in the topic. Whereas, Surface Approaches are when students are reluctant to understand the topic deeply; rather, there is a preference to do the minimum expected without failing. 
Together, these three approaches (Achieving, Deep, and Surface) and Motive-Strategy decomposition provides a 3x2 model of learning approaches.

To measure the constructs of the 3x2 model (i.e., Deep-Motive, Surface-Strategy, Achieving-Strategy), Biggs developed and validated the SPQ (Study Process Questionnaire; Biggs, 1987). With his colleagues, he later revised this to become the R-SPQ-2F (Biggs et al., 2001). What differentiates the R-SPQ-2F from the SPQ, apart from the reduction in item numbers, is the removal of the Achieving Approach constructs. This was on account of the ambiguity of measuring Achieving Approaches to monitor learning environments compared to either the Deep and Surface factors (Biggs et al., 2001). The development of the R-SPQ-2F was therefore about measuring a 2x2 model: Deep-Motive, Deep-Strategy, Surface-Motive, and Surface-Strategy.

\section{Proposed Models of Learning Approaches}

In the original work of Biggs et al. (2001), they tested two models using R-SPQ-2F data (Figure 1 and 2). The Comparative Fit Index (CFI) and Standardized Root Mean Square Residual (SRMR) were used to evaluate each model. On face value, the fits of the presented models were satisfactory. Although Model B (two higher-order factors each measure by two first-order factors; Figure 2 appeared favourable, it should be viewed with caution as item parcelling may have masked model misspecifications (e.g., cross-loadings; Marsh et al., 2013). The work of Fryer et al. (2012) illustrates this as well. For these authors, an item-based four-factor model was far from perfect (CFI $=.78$, TLI $($ Tuker-Lewis Index $)=.73$, RMSEA $($ Root Mean Square Error of Approximation $)=.063)$. Upon aggregation at a sub-scale (i.e., Deep-Strategy) level, the model fit improved (CFI = $1, \mathrm{TLI}=1, \mathrm{RMSEA}=0$ ). Although preferential from a model fit perspective, it precludes an exploration of item misspecification (e.g., problematic factor loadings). For this reason, the present focus is on item-based representations of the R-SPQ- $2 \mathrm{~F}$ factor structure.

[Figure 1 Here] 
[Figure 2 Here]

Subsequent item-based investigations into the factor structure of the R-SPQ-2F have resulted in findings that are contradictory to those reported by Biggs et al. (2001) (Table 1). The work of Justicia et al. (2008) is one such example. Through the evaluation of four model representations, Justicia et al. found the best fitting model to include two factors representing Deep and Surface Approaches (Table 1). The authors found no evidence to support the decomposition of Deep and Surface factors into respective Motive and Strategy factors. Xie (2014) drew similar conclusions and found a better model fit for a two-factor (Deep and Surface Approaches) model over a four-factor model (Deep-Strategy, Deep-Motive, Surface-Strategy, and Surface-Motive; Table 11. However, Johnson et al. (2021) found this two-factor model fit to be far from good.

Immekus and Imbrie (2010) evaluated the suitability of a four first-order factor model. The model deviated from Biggs et al. (2001) as all factors were free to correlate. Biggs et al. (2001) only specified factor-correlations between Deep-Strategy and Deep-Motive, Surface-Strategy and Surface-Motive, and Deep-Motive and Surface-Motive. Immekus and Imbrie did not provide overwhelming support-based on CFI, RMSEA, and SRMR - for a four-factor model (Table 1). High inter-factor correlations (Deep-Strategy and Deep-Motive $=.96 ;$ Surface-Strategy and Surface-Motive $=.90$ ) also highlighted issues of discriminant validity. Thus, a four-factor model appeared as an over-extraction. Immekus and Imbrie additionally evaluated a two-factor model (Deep and Surface Approach factors). Contrary to what Justicia et al. (2008) reported, Immekus and Imbrie did not find support for a two-factor model (Table 1). The model eventually accepted by Immekus and Imbrie - reassessed using exploratory factor analysis - was a four-factor model with five items being dropped (Table 1).

Socha and Sigler (2014) tested a series of different model representations (first-order, hierarchical, and bi-factor) based on the work of Biggs et al. (2001), Justicia et al. (2008), and Immekus and Imbrie (2010). Models proposed by Biggs et al. were non-admissible. 
The 15-item, four-factor model offered by Immekus and Imbrie met the commonly used Hu and Bentler (1999) criteria $(\mathrm{CFI}=.95, \mathrm{TLI}=.95, \mathrm{RMSEA}=.06, \mathrm{SRMR}=.08$; Table 1). However, item loadings distorted factor definitions. Socha and Sigler settled on a two-factor model (Deep and Surface Approaches) with two items being omitted. López-Aguado and Gutiérrez-Provecho (2018) also found support for this model (Table 1). Shahrazad et al. (2013) found support for a two-factor (Deep and Surface) model, with six items being dropped based on modification indices and factor loadings (Table 1). A limitation here is the use of modification indices that may reflect sampling fluctuations. Finally, Zakariya et al. (2020) offer an alternate two-factor (Deep and Surface Approaches) model, with one item removed based on having a nominal target factor loading.

Previous research has also explored a hierarchical model proposed by Biggs et al. (2001), whereby two factors of Deep and Surface are each measured by two first-order factors (Motive and Strategy). Justicia et al. (2008) found the fit to meet what could be considered acceptable (Table 1). Socha and Sigler (2014), on the other hand, found this model to not converge. Zakariya et al. (2020) found the hierarchical model to converge, but the fit was inadequate (Table 1). A hierarchical model requires, at a minimum, three first-order factors loading to be identified (Kline, 2015). Therefore, it is preferable to keep focus on first-order factor models (i.e., Deep-Motive) in lieu of a higher-order representation (i.e., Deep and Surface Approaches).

[Table 1 Here]

\section{Research Aim}

The aim of this work is to review the initially proposed R-SPQ-2F factor structure (Biggs et al., 2001). Although similar undertakings have been carried out by others (Immekus \& Imbrie, 2010; Justicia et al., 2008 López-Aguado \& Gutiérrez-Provecho, 2018. Shahrazad et al., 2013; Socha \& Sigler, 2014; Xie, 2014; Zakariya et al., 2020), this has resulted in a mixture of model representations. With little consensus as to what factor 
structure to agree upon, this may have deleterious down-stream effects. That is, research findings could be based on variation of items from the R-SPQ- $2 \mathrm{~F}$, which is wholly dependent on which paper is initially selected. Thus, we pose the following research question:

- What factor model is the best representation for items of the R-SPQ-2F? (Research Question 1; RQ1)

By answering this question, the paper attempts to identify a preferential factor model for the R-SPQ-2F. We discuss any problematic items identified through such analysis. This remains a constructive venture to support practitioners and researchers intending to use the instrument. Thus, the focus is on identifying areas of improvement (e.g., item re-writes), as opposed to model critiques.

\section{Method}

\section{Sample}

A total of 1,636 student (Undergraduate and Postgraduate) responses were initially collected using opportunity sampling from an Australian University. Of the 1636 responses, $456(27.873 \%)$ contained missing values for all 20 items and $4(.244 \%)$ responses contained missing student identification details. The 456 missing responses were omitted, in addition to those with 4 instances of missing personal details. Having personal details was a necessity for the analysis to determine how representative the sample was of the student population; thus, they were omitted. Eighteen (1.100\%) responses were identified as being duplicates on the basis of the student identification information; all responses given by these students (original and duplicate) were dropped.

One-thousand and fifty eight $(1,158)$ complete responses were retained for the analyses that followed. The gender breakdown for the sample was as follows: 737 (63.60\%) Female, 419 (36.20\%) Male, and 2 (.173\%) Indeterminate/Intersex/Unspecified. To 
evaluate the sample characteristics, they can be compared to the student population from which they were sampled. Across the University, the gender counts and percentages are as follows: 47,629 (56.60\%) Female, 36,410 (43.30\%) Male, and $44(.052 \%)$

Indeterminate/Intersex/Unspecified students. Ages of the respondents in the sample ranged from 17 to $53(M=21.60, S D=4.74$, Skewness $=3.25)$. For the student population, age ranged from 15 to $87(M=23.30, S D=6.56$, Skewness $=2.77$; sample and population age distributions are presented in Appendix $\mathrm{A}$. The number of Undergraduate students totalled 905 (78.20\%), whilst 253 (21.80\%) were Postgraduate students. The University population values for course levels were as follows: 4812 (5.72\%, Higher Degree Research), 24,495 (29.10\%, Postgraduate), 54,351 (64.60\%, Undergraduate), and 425 (.505\%, Non-Award). Of the 10 academic disciplines at the university, all but one (Pharmacy and Pharmaceutical Sciences) was represented (Table 2).

[Table 2 Here]

Comparing the sample to the 2019 Academic Discipline enrolment data (Table 2), it was clear that the student population was not well represented. In certain cases, Academic Disciplines were under-represented: Art, Design, and Architecture, Arts, Education, Law, Medicine, Nursing, and Health Sciences, and Pharmacy and Pharmaceutical Sciences. Whereas, the Academic Disciplines of Business and Economics, Engineering, Information Technology, and Science were over-represented in the sample.

\section{Instrument}

Data was collected using the 20-item R-SPQ-2F (Appendix B Biggs et al., 2001). Slight amendments were made to the item wordings to align with the institutional context. In the original item wordings Biggs et al. referred to course (e.g., My aim is to pass the course while doing as little work as possible); for the context of this study, unit was a more appropriate wording choice (e.g., My aim is to pass the unit while doing as little work 
as possible). Each of the 20-items were answered on a 5-point Likert scale ranging from This is never or only rarely true of me (1) to This is always or almost always true of me (5).

\section{Procedure}

Survey links for the R-SPQ-2F Biggs et al., 2001 were distributed to students (Undergraduates and Postgraduates) through direct emails. To receive the email, the student had to be enrolled within a course using live-streaming services. The R-SPQ-2F was used as a set of introductory items before a series of items designed to measure live streaming attitudes; results of the latter are not applicable to the current work. Completion of the survey was voluntary; respondents to the survey were eligible to participate in a voluntary prize-draw to win one of five $\$ 20$ gift cards. Respondents were

only able to access the survey by using their university credentials, which were logged and used to connect survey responses to demographic and educational information. An explanatory statement form was given to students before completing the survey detailing how their university credentials would be collected and used to connect responses to university records; consent was obtained from all respondents. Institutional ethical approval was obtained for all of this work.

\section{Analysis}

To answer RQ1, we tested three models (Figure 3) using Confirmatory Factor Analysis (CFA) and Exploratory Structural Equation Modelling (ESEM; Figure 3). Response distributions for the 20 items (Appendix B) showed non-normality, a commonality with ordinal level data. Thus, we used the weighted least square mean and variance adjusted (WLSMV) estimator with delta scaling. All analyses used Mplus 8.3 (Muthén \& Muthén, 2017).

Both the original work of Biggs et al. (2001) and work that followed (Fryer et al., 2012; Immekus \& Imbrie, 2010 Justicia et al., 2008; López-Aguado \& Gutiérrez-Provecho, 2018: Socha \& Sigler, 2014; Xie, 2014) informed the models tested. Figure 3a (Model 1) is 
the item-level model proposed by Biggs et al. For this model, five items measure each of the four factors: Deep-Motive, Deep-Strategy, Surface-Motive, and Surface-Strategy. The model specifies factor correlations between Motive and Strategy within the same approach (Surface-Motive and Surface-Strategy), and limits across approach correlations to the Deep-Motive and Surface-Motive factors. Figure 3p (Model 2) deviates from Model 1 by allowing all factors to freely correlate. This model is a reasonable adjustment to Figure $3 \mathrm{a}$ (Model 1), as the inclination of a student using a Surface-Strategy toward using a strategy focused on obtaining a deep understanding of the subject (Deep-Strategy) would be lower. The findings of Justicia et al. (2008) informed Figure 3c (Model 3). Specifically, the finding that a two-factor (Deep and Surface) representation offers a better fit to the data over a four-factor model. It also accounts for the high correlation between Motive and Strategy factors that are reported (Immekus \& Imbrie, 2010). Table 3 presents the indicator to factor specification for each model.

[Figure 3 Here]

[Table 3 Here]

Figure 3 presents confirmatory factor models with the assumptions of no cross-loading factors and no correlated errors. As discussed by Marsh et al. (2014), the restriction of zero cross-loadings is too restrictive because of indicator fallibility. Marsh et al. instead advocate the use of ESEM, wherein the analyst can specify items to load onto multiple factors. This may be a suitable reflection of reality as items may have nominal loadings onto non-target factors; without specification, the latter may result in sources of ill-fit. The recommendation outlined by Marsh et al. (2014) was therefore followed: a confirmatory factor model was first tested, followed by an ESEM. ESEM was applied to all but Model $3 \mathrm{a}$ as a target oblique rotation procedure was used, wherein all factor correlations are freely estimated. For the target rotation, the only factor loadings specified $(=0)$ were those items - based on the work of Biggs et al. (2001) and Justicia et al. 
(2008) — not loading onto the target factors. We made no specifications for indicators with target factors (Table 3).

How the ESEM models differed from those presented in Figure 3 was the permittance of cross-loadings; no ESEM model specified correlated errors. We compared models (CFA and ESEM) using general fit measures ( $\chi^{2}$, CFI, TLI, RMSEA, and SRMR), local fit (residuals), and measurement quality (factor loadings). Model evaluation made use of the regularly cited cut-offs for fit indices $(\mathrm{CFI}=.95, \mathrm{TLI}=.95, \mathrm{RMSEA}=.06$, SRMR $=.08 ; \mathrm{Hu}$ and Bentler, 1999). As a narrow range of models informed these cut-off values, they may not reflect those models tested (Marsh et al., 2004). Global fit indices only served as one element in the model evaluation. We, therefore, supplemented global fit interpretation with an assessment of how well indicators measure the construct of interest and an exploration of potential sources of misfit. Two approaches were used to identify sources of localised strain in the models: residual correlations, using $\geq .10$ as a guideline Kline, 2015, and modification index (MI) and standardised/expected parameter change (S/EPC) values (Saris et al., 2009). This model evaluation helped determine a suitable candidate factor model (Model 1-3; RQ1).

With 20 indicators, the number of observations totalled 270 (190 polychoric correlations and 80 thresholds). For Model 1, the confirmatory factor model required 103 parameters to be estimated (16 factor loadings, 80 thresholds, 3 factor covariances, and 4 factor variances), equating to 167 degrees of freedom ( $d f)$. For Model 2, the confirmatory factor model estimated 106 parameters (16 factor loadings, 80 thresholds, 6 factor covariances, and 4 factor variances; $d f=164$ ). The ESEM model required 154 parameters to be estimated (74 factor loadings and 80 thresholds; $d f=116$ ). Model 3 required 101 paramaters to be freely estimated for the CFA (18 factor loadings, 80 thresholds, 1 factor covariance, and 2 factor variances; $d f=169$ ) and 119 for the ESEM (39 factor loading and 80 thresholds; $d f=151$ ). In all instances, the models were overidentified. 


\section{Results}

\section{Model 1}

The first confirmatory factor model (Model 1; Figure 3a) resulted in a latent variable covariance matrix that was not positive definite. A detailed inspection of the output showed estimated correlations between latent variables to exceed the value of one (Deep-Motive and Deep-Strategy $=1.008 ;$ Surface-Motive and Surface-Strategy $=1.032)$.

\section{Model 2}

CFA Model. When all inter-factor correlations are specified (Model 2; Figure 3b) in the confirmatory factor model, the results were again not positive definite. This was attributed to the correlations between the constructs of a particular approach exceeding 1 (Deep-Motive and Deep-Strategy $=1.008 ;$ Surface-Motive and Surface-Strategy $=1.030$ ).

ESEM Model. The ESEM version of Model 2 converged; $\chi^{2}(116)=695.729, p<$ $.001, \mathrm{CFI}=.948, \mathrm{TLI}=.915, \mathrm{RMSEA}=.066(90 \% \mathrm{CI}=.061-.070), \mathrm{SRMR}=.026$. Inter-factor correlations were small (Table 4). A low to moderate amount of the underlying continuous latent response variables was accounted for by the factors $\left(R^{2}=.309-636\right)$. Nine instances of residual variances being $>50 \%$ were identified (Table 5).

\section{[Table 4 Here]}

Factor loadings are presented in Table 5, showing the following absolute value ranges:

- .021-.589 ( $M=.276 ;$ Deep-Motive $)$;

• .082-.670 $(M=.282 ;$ Deep-Strategy $)$;

- .005-.670 (M=.274; Surface-Motive $) ;$ and

- .013-.706 ( $M=.216 ;$ Surface-Strategy $)$. 
Focusing on target factor loadings only, $|\lambda|$ values ranged from:

•.172-.589 ( $M=.453 ;$ Deep-Motive $)$;

- .082-.670 (M =.404; Deep-Strategy $)$;

- .202-.670 ( $M=.524 ;$ Surface-Motive $) ;$ and

- .240-.706 $(M=.385 ;$ Surface-Strategy $)$.

[Table 5 Here]

An inspection of the residual correlation matrix (Appendix C) showed three locations with absolute values $\geq .10$. The areas of localised strain are presented in Appendix C, along with MI and S/EPC values.

\section{Model 3}

CFA Model. Model 3 (Figure 3c), as a confirmatory factor model, successfully converged and was positive definite. The obtained fit was as follows: $\chi^{2}(169)=1844.252, p$ $<.001, \mathrm{CFI}=.851, \mathrm{TLI}=.832, \mathrm{RMSEA}=.093(90 \% \mathrm{CI}=.089-.096)$, and SRMR $=$ .066. Both unstandardised and standardised factor loadings for the model are presented in Table 6. Standardised loadings ranged from:

•.513-.769 (M = .662; Deep Approach); and

- .513-.733 (M=.618; Surface Approach).

The two factors of Deep Approach and Surface Approach were not strongly correlated $(r=-.107)$. A low to moderate amount of the variance in the latent continuous response variables is accounted for by the factors $\left(R^{2}=.263-.592\right)$. Residual variances for 15 of the 20 indicators showed the factors to account for less than $50 \%$ of the latent response variable (Table 6). 
Residual correlations for the CFA model are presented in Appendix D, wherein 41 sources of ill-fit can be identified using $\geq .10$ as a cut-off. Table $\mathrm{D}$ presents the residual correlations that were $\geq .10$, along with MI, EPC, and SEPC values.

[Table 6 Here]

ESEM Model. The ESEM version of Model 3 converged and achieved a slightly improved global fit over the confirmatory factor model, $\chi^{2}(151)=1607.452, p<.001$, CFI $=.870, \mathrm{TLI}=.837, \mathrm{RMSEA}=.091(90 \% \mathrm{CI}=.087-.095)$, and SRMR $=.043$. The inter-factor correlation was found to be low (-.090). Loadings are presented in Table 7 . with $|\lambda|$ values ranging from:

- .020-.771 ( $M=.383 ;$ Deep Approach $) ;$ and

- .000-.708 ( $M=.337 ;$ Surface Approach $)$.

For target factor loadings, the $|\lambda|$ values ranged from:

• .527-.771 ( $M=.662 ;$ Deep Approach $) ;$ and

- .486-.708 $(M=.618 ;$ Surface Approach $)$.

A low to moderate amount of the underlying continuous latent response variable was accounted for by the factors $\left(R^{2}\right.$ range $\left.=.252-.591\right)$. There were 15 instances of residual variance values being $>50 \%$ (Table 7 ).

\section{[Table 7 Here]}

The residual correlation matrix (Appendix D) showed nine locations where absolute values $\geq .10$. Appendix $\mathrm{D}$ presents the locations at which this localised strain within the model occurs, along with MI, EPC, and SEPC values. 


\section{Discussion}

Results show the four-factor model (the adapted Biggs et al. (2001) model; Figure 3b) to be the best representation when analysing items of the R-SPQ-2F (RQ1), contrary to prior works (Justicia et al., 2008; Xie, 2014). This is both informed by global fit and local fit measures. There are two caveats, however. First, this only applies to the use of ESEM, not CFA. Second, this came at the expense of clear factor definitions. What follows is a discussion of these problematic items in Model 2 (ESEM).

\section{Distorted Factor Definitions}

Model 2 (ESEM) factor loadings showed eight items (2, 4, 6, 9, 10, 12, 16, and 20) that resulted in distorted factor definitions. Simply put, items loaded onto factors that were contrary to those previously hypothesised (Biggs et al., 2001).

Item 2's (I find that I have to do enough work on a topic so that I can form my own conclusions before I am satisfied) hypothesised target factor is Deep-Strategy. The results here show a target factor (Deep-Strategy) loading of .082, with a moderate loading onto Deep-Motive $(\lambda=.574)$. Item 2 is asking about satisfaction, similar to Item 1 (I find that at times studying gives me a feeling of deep personal satisfaction). Therefore, it is possible that there is a wording effect because of the items being framed around the feeling of satisfaction that arises from studying. Item 2 is also asking why the student approaches the task (i.e., to form conclusions), which maps more with a motivation than a strategy.

Item 4 (I only study seriously what's given out in class or in the unit guide) had a higher factor loading for Surface-Motive $(\lambda=.334)$ than its target factor of Surface-Strategy $(\lambda=.240)$. Based on these loadings, Item 4 is an imperfect measure of either the Surface-Strategy or Surface-Motive factors. From an item wording perspective, there are additional complexities. The item is asking if the student studies seriously, which does not convey explicit details on the strategy or the motive. A further issue of the item is its context dependency (Johnson et al., 2021). For some classes, the requirement may 
simply equate to having a thorough understanding of the material.

Proposed as an indicator of Deep-Strategy, Item 6 (I find most new topics interesting and often spend extra time trying to obtain more information about them) showed similar issues of moderate loadings on the target factor $(\lambda=.558)$ and a non-target factor (Deep-Motive; $\lambda=.445$ ). As Item 6 asks students about their interest in a topic, this clearly taps into the Motive facet as it is asking why the student is approaching the task. The latter half of the item explores the Strategy factor by asking how they approach the task, specifically by allocating more time. Thus, the item problems are from it being 'double-barrelled', resulting in students answering either the Motive or Strategy aspect of the item Bandalos, 2018. This is the reason that Item 6 does not function well as a measure of a single factor (Deep-Strategy).

Item 9 (I find that studying academic topics can at times be as exciting as a good novel or movie $)$ cross-loaded on both Deep-Strategy $(\lambda=.422)$ and Deep-Motive $(\lambda=$ .451). While this item appears to touch upon motivations for the approach, specifically the excitement students experience whilst studying, it is not explicit in asking whether this is the underlying reason. There is good reason to view this item as measuring Deep-Strategy too, as it seeks to evaluate the strategy used. Put differently, students are being asked if they find the act of studying to be exciting. This is a different perspective than a question asking if a student studies because of the satisfaction that arises.

Item 10 (I test myself on important topics until I understand them completely) had two problems. One, it had a low target factor loading $\left(\lambda_{\text {Deep-Strategy }}=.253\right)$. Two, it had low to moderate non-target factor loadings $\left(\lambda_{\text {Deep-Motive }}=.403 ; \lambda_{\text {Surface-Strategy }}=.315\right)$. These issues may stem from the wording itself. It reads as a Surface-Strategy item by asking if the student repeats a behaviour (testing) until they understand the topic. A repetitive behaviour such as this is reminiscent of rote learning, depending on the interpretation of test. Item 10 also reads as a Deep-Motive item by asking if the strategy is about wanting a complete understanding of the topic. Thus, the item explores the 
reasoning behind the adopted approach (i.e., to improve topic understanding), in addition to the strategy adopted. In sum, Item 10 bears semblance to an array of factors that it was not intended to measure.

Factor loading values for Item 12 (I generally restrict my study to what is specifically set as I think it is unnecessary to do anything extra) raise questions as to what is being measured. The highest factor loading was for a non-target factor $\left(\lambda_{\text {Surface-Motive }}=\right.$ $.410)$, although the target factor loading value was moderate $\left(\lambda_{\text {Surface-Strategy }}=.371\right)$. Wording of this item is problematic as it encompasses two themes: Motive and Strategy. The first part of the statement asks about how the student approaches their studying, i.e. restricting the amount studied. The second half, however, asks about the underlying motivation for the approach adopted (the student sees any additional work as unnecessary). There are two things essentially being asked of students with Item 12, what is their approach (Strategy) and why adopt this approach (Motive).

With Item 16 (I believe that lecturers shouldn't expect students to spend significant amounts of time studying material), loadings are higher for non-target factors ( $\lambda_{\text {Deep-Motive }}$ $\left.=.297 ; \lambda_{\text {Surface-Motive }}=.465\right)$ than the target factor $\left(\lambda_{\text {Surface-Strategy }}=.270\right)$. A moderate loading on the Surface-Motive factor is understandable as the item asks students about their motivations for adopting a particular approach (the belief that lecturers should not expect such workload levels from students). For the Deep-Motive factor, item 16's loading is not straightforward. Being negatively phrased, there is a possibility that this presents a difficult item for students to respond to. For example, a student who agrees with the statement has to respond with 'This is never or only rarely true of me'. It may be necessary for work to explore interpretations of this item by respondents to explore if there are any associated difficulties.

Finally, Item 20 (I find the best way to pass examinations is to try to remember answers to likely questions) had low loadings on its target factor (Surface-Strategy; $\lambda=$ .339), which were comparable to the non-target factor loading on Surface-Motive ( $\lambda=$ 
.324). This is another instance where an item taps into two constructs. There is an element of Motive by framing the statement around passing an exam, and an element of Strategy in trying to remember answers to likely questions.

\section{Conclusion}

Validity concerns with the R-SPQ-2F are not exclusive to this work (Johnson et al., 2021). The study results reiterate the need for an item re-write. A plethora of models and item combinations is not helpful for researchers intending on using the measure when item wordings remain an issue. Thus, insisting on dropping items is unlikely to correct the underlying problem. Researchers need to work on bringing clarity to the 20 R-SPQ-2F items, be that through removing ambiguous terminology or by removing compound sentences. Without doing so, we may wrongly conclude that four-factors are being measured, despite distorted factor definitions. The R-SPQ-2F can continue to be a helpful tool for education research, but only if more work is done to correct the identified problematic areas.

Those intent on using the R-SPQ-2F should be mindful of the validity concerns raised here. At face-value, four-factors appear reasonable. It is only upon closer inspection we identify misspecifications. Thus, with each usage of the R-SPQ-2F researchers and practitioners should evaluate the construct validity using exploratory factor analysis and report problematic items. Without these necessary steps, this could have deleterious downstream effects on educational research, as we may not be measuring what we intend to be measuring.

\section{Limitations}

Data was obtained through the use of opportunity sampling, as opposed to the use of stratified or random sampling approaches. Based on the sample and population demographic breakdowns, it was clear that the sample was not representative. Follow-up 
work should seek to obtain a more representative sample of the student population, which is also large enough to conduct measurement invariance tests across various sub-groups. 


\section{References}

Bandalos, D. L. (2018). Measurement Theory and Applications for the Social Sciences. Guilford Publications.

Biggs, J. B. (1987). Student Approaches to Learning and Studying. Research Monograph. Australian Council for Educational Research Ltd.

Biggs, J. B., Kember, D., \& Leung, D. Y. P. (2001). The revised two-factor Study Process Questionnaire: R-SPQ-2F. British Journal of Educational Psychology, 71(1), 133-149. https://doi.org/10.1348/000709901158433

Bliuc, A.-M., Ellis, R., Goodyear, P., \& Piggott, L. (2010). Learning through face-to-face and online discussions: Associations between students' conceptions, approaches and academic performance in political science [__eprint: https://onlinelibrary.wiley.com/doi/pdf/10.1111/j.1467-8535.2009.00966.x]. British Journal of Educational Technology, 41(3), 512-524. https://doi.org/10.1111/j.1467-8535.2009.00966.x

Fryer, L. K., Ginns, P., Walker, R. A., \& Nakao, K. (2012). The adaptation and validation of the CEQ and the R-SPQ-2F to the Japanese tertiary environment. British Journal of Educational Psychology, 82(4), 549-563. https://doi.org/10.1111/j.2044-8279.2011.02045.x

Gašević, D., Jovanović, J., Pardo, A., \& Dawson, S. (2017). Detecting learning strategies with analytics: Links with self-reported measures and academic performance. Journal of Learning Analytics, 4(2), 113-128.

Ginns, P., \& Ellis, R. (2007). Quality in blended learning: Exploring the relationships between on-line and face-to-face teaching and learning. The Internet and Higher Education, 10(1), 53-64. https://doi.org/10.1016/j.iheduc.2006.10.003

Hu, L.-t., \& Bentler, P. M. (1999). Cutoff criteria for fit indexes in covariance structure analysis: Conventional criteria versus new alternatives. Structural Equation 
Modeling: A Multidisciplinary Journal, 6(1), 1-55.

https://doi.org/10.1080/10705519909540118

Immekus, J. C., \& Imbrie, P. (2010). A Test and Cross-Validation of the Revised

Two-Factor Study Process Questionnaire Factor Structure Among Western

University Students. Educational and Psychological Measurement, 70 (3), 495-510. https://doi.org/10.1177/0013164409355685

Johnson, S. N., Gallagher, E. D., \& Vagnozzi, A. M. (2021). Validity concerns with the Revised Study Process Questionnaire (R-SPQ-2F) in undergraduate anatomy \& physiology students [Publisher: Public Library of Science]. PLOS ONE, 16(4), e0250600. https://doi.org/10.1371/journal.pone.0250600

Justicia, F., Pichardo, M. C., Cano, F., Berbén, A. B. G., \& De la Fuente, J. (2008). The Revised Two-Factor Study Process Questionnaire (R-SPQ-2F): Exploratory and confirmatory factor analyses at item level. European Journal of Psychology of Education, 23(3), 355-372. https://doi.org/10.1007/BF03173004

Kline, R. B. (2015). Principles and Practice of Structural Equation Modeling, Fourth Edition [Google-Books-ID: HyavCgAAQBAJ]. Guilford Publications.

López-Aguado, M., \& Gutiérrez-Provecho, L. (2018). Checking the underlying structure of R-SPQ-2F using covariance structure analysis / Comprobación de la estructura subyacente del R-SPQ-2F mediante análisis de estructura de covarianza. Cultura y Educación, 30(1), 105-141. https://doi.org/10.1080/11356405.2017.1416787

Marsh, H. W., Hau, K.-T., \& Wen, Z. (2004). In Search of Golden Rules: Comment on Hypothesis-Testing Approaches to Setting Cutoff Values for Fit Indexes and Dangers in Overgeneralizing Hu and Bentler's (1999) Findings. Structural Equation Modeling: A Multidisciplinary Journal, 11(3), 320-341. https://doi.org/10.1207/s15328007sem1103_2

Marsh, H. W., Lüdtke, O., Nagengast, B., Morin, A. J. S., \& von Davier, M. (2013). Why item parcels are (almost) never appropriate: Two wrongs do not make a 
right - Camouflaging misspecification with item parcels in CFA models. Psychological Methods, 18(3), 257-284. https://doi.org/10.1037/a0032773

Marsh, H. W., Morin, A. J. S., Parker, P. D., \& Kaur, G. (2014). Exploratory structural equation modeling: An integration of the best features of exploratory and confirmatory factor analysis. Annual review of clinical psychology, 10, 85-110. https://doi.org/10.1146/annurev-clinpsy-032813-153700

Muthén, L., \& Muthén, B. (2017). Mplus User's Guide.

Saris, W. E., Satorra, A., \& Veld, W. M. v. d. (2009). Testing Structural Equation Models or Detection of Misspecifications? [Publisher: Routledge _eprint: https://doi.org/10.1080/10705510903203433]. Structural Equation Modeling: A Multidisciplinary Journal, 16(4), 561-582. https://doi.org/10.1080/10705510903203433

Shahrazad, W. S. W., Sulaiman, W. S. W., \& Dzulkifli, M. A. (2013). Reliability of Second-order Factor of a Revised Two-factor Study Process Questionnaire (R-SPQ-2F) among University Students in Malaysia. ASEAN Journal of Teaching E Learning in Higher Education, 5(2), 1-13.

Socha, A., \& Sigler, E. A. (2014). Exploring and "reconciling" the factor structure for the Revised Two-factor Study Process Questionnaire. Learning and Individual Differences, 31, 43-50. https://doi.org/10.1016/j.lindif.2013.12.010

Xie, Q. (2014). Validating the Revised Two-Factor Study Process Questionnaire among Chinese University Students. The International Journal of Educational and Psychological Assessment, 16(1), 18.

Zakariya, Y. F., Bjørkestøl, K., Nilsen, H., Goodchild, S., \& Lorås, M. (2020). University students' learning approaches: An adaptation of the revised two-factor study process questionnaire to Norwegian. Studies in Educational Evaluation, 64, 100816. https://doi.org/10.1016/j.stueduc.2019.100816 


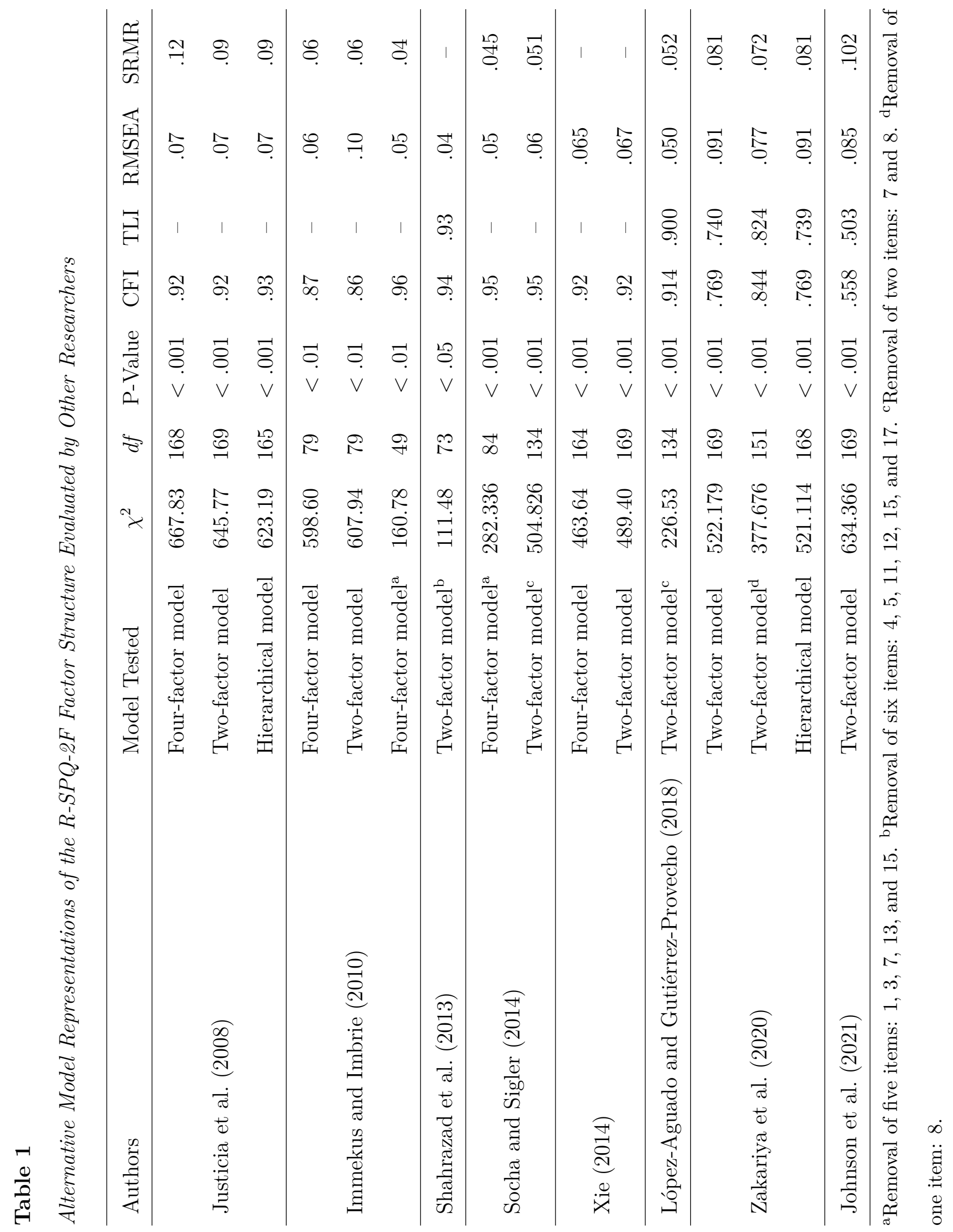




\section{Table 2}

Sample and 2019 Population Academic Discipline Enrolment Counts and Percentages

\begin{tabular}{lcccc}
\hline & \multicolumn{2}{c}{ Sample } & \multicolumn{2}{c}{ Population } \\
Academic Discipline & $n$ & $\%$ & $n$ & $\%$ \\
\hline Art, Design, and Architecture & 21 & 1.81 & 2773 & 3.30 \\
Arts & 90 & 7.77 & 7954 & 9.47 \\
Business and Economics & 341 & 29.40 & 21007 & 25.00 \\
Education & 87 & 7.51 & 7079 & 8.42 \\
Engineering & 179 & 15.50 & 9011 & 10.70 \\
Information Technology & 137 & 11.80 & 7169 & 8.53 \\
Law & 32 & 2.76 & 4095 & 4.87 \\
Medicine, Nursing, and Health Sciences & 127 & 11.00 & 15893 & 18.90 \\
Pharmacy and Pharmaceutical Sciences & - & - & 2546 & 3.03 \\
Science & 144 & 12.40 & 6500 & 7.74 \\
\hline
\end{tabular}

\section{Table 3}

Indicator to Factor Specification for 3 Tested Models (Item wordings presented in Appendix 1.2)

\begin{tabular}{clc}
\hline Model & Factor & \multicolumn{2}{c}{ Items } \\
\hline \multirow{2}{*}{$1 \& 2$} & Deep-Motive & 1591317 \\
& Deep-Strategy & 26101418 \\
& Surface-Motive & 37111519 \\
& Surface-Strategy & 48121620 \\
\hline \multirow{2}{*}{3} & Deep Approach & 125691013141718 \\
& Surface Approach & 3478111215161920 \\
\hline
\end{tabular}




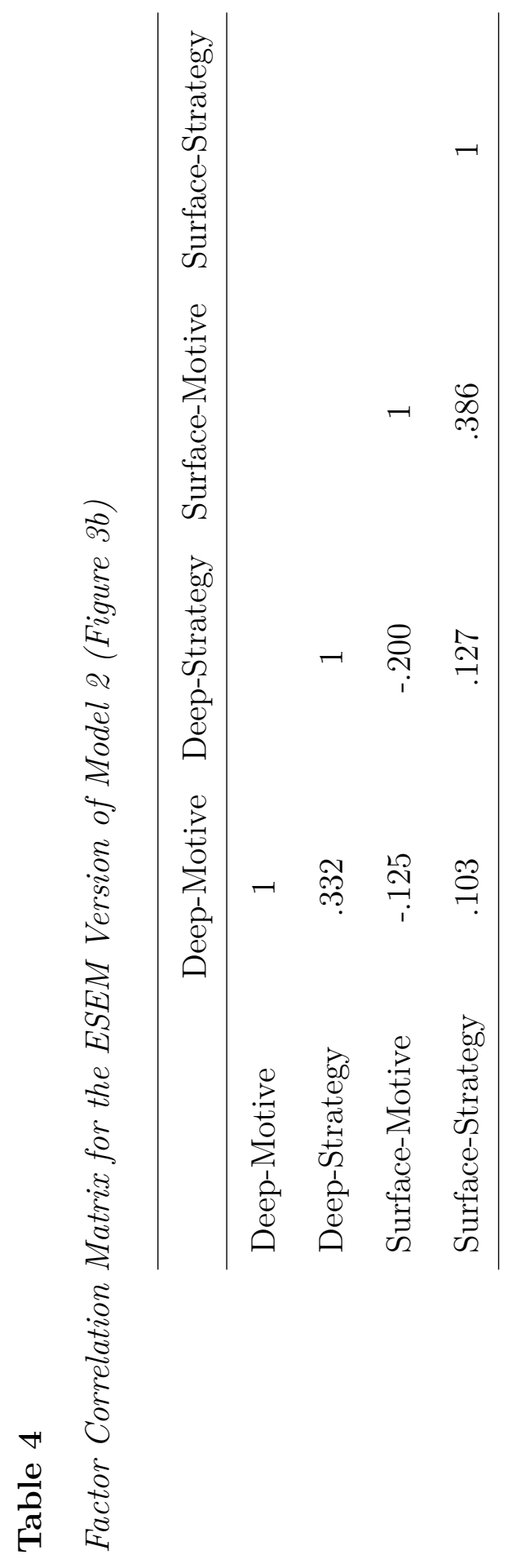




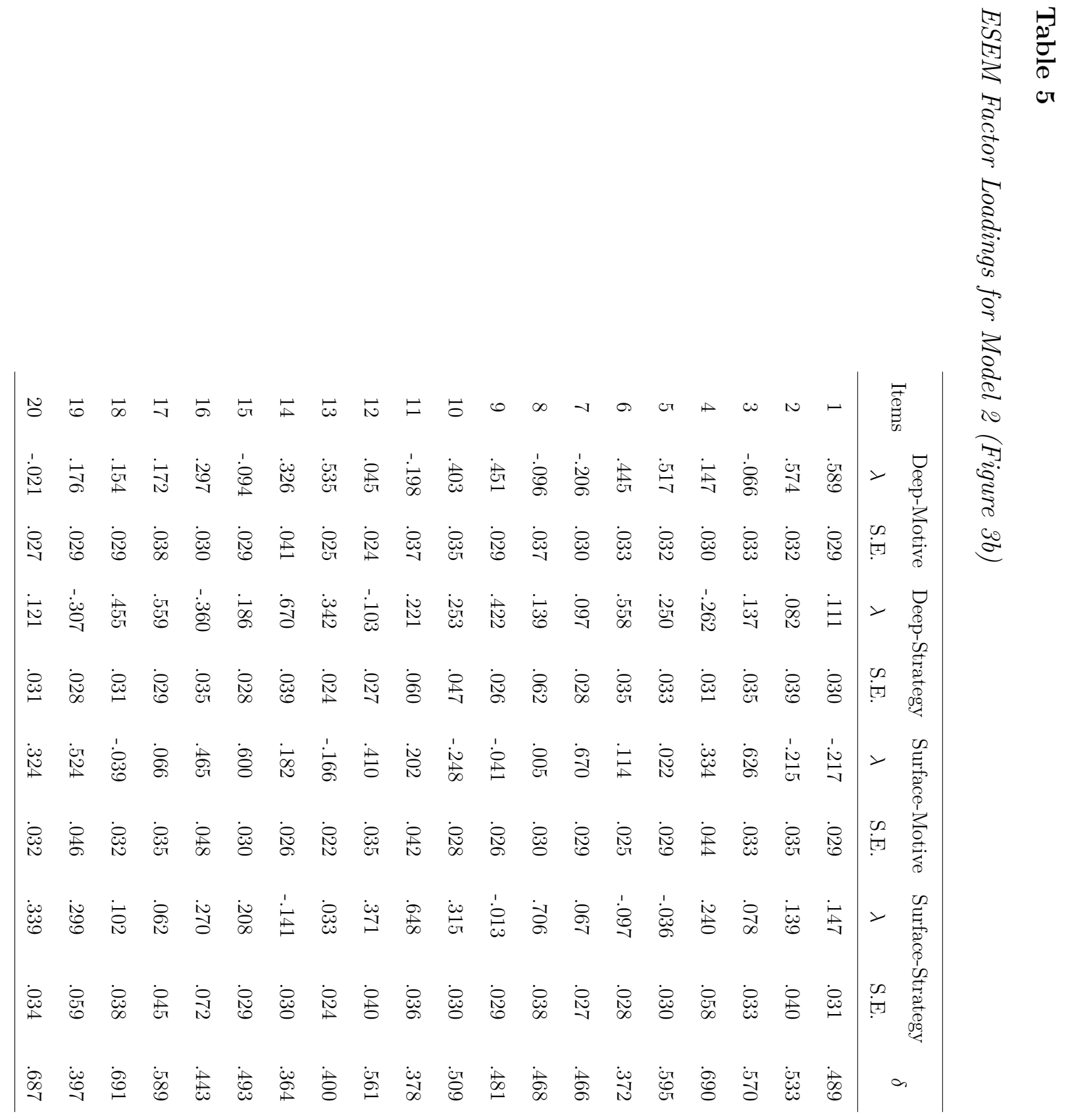




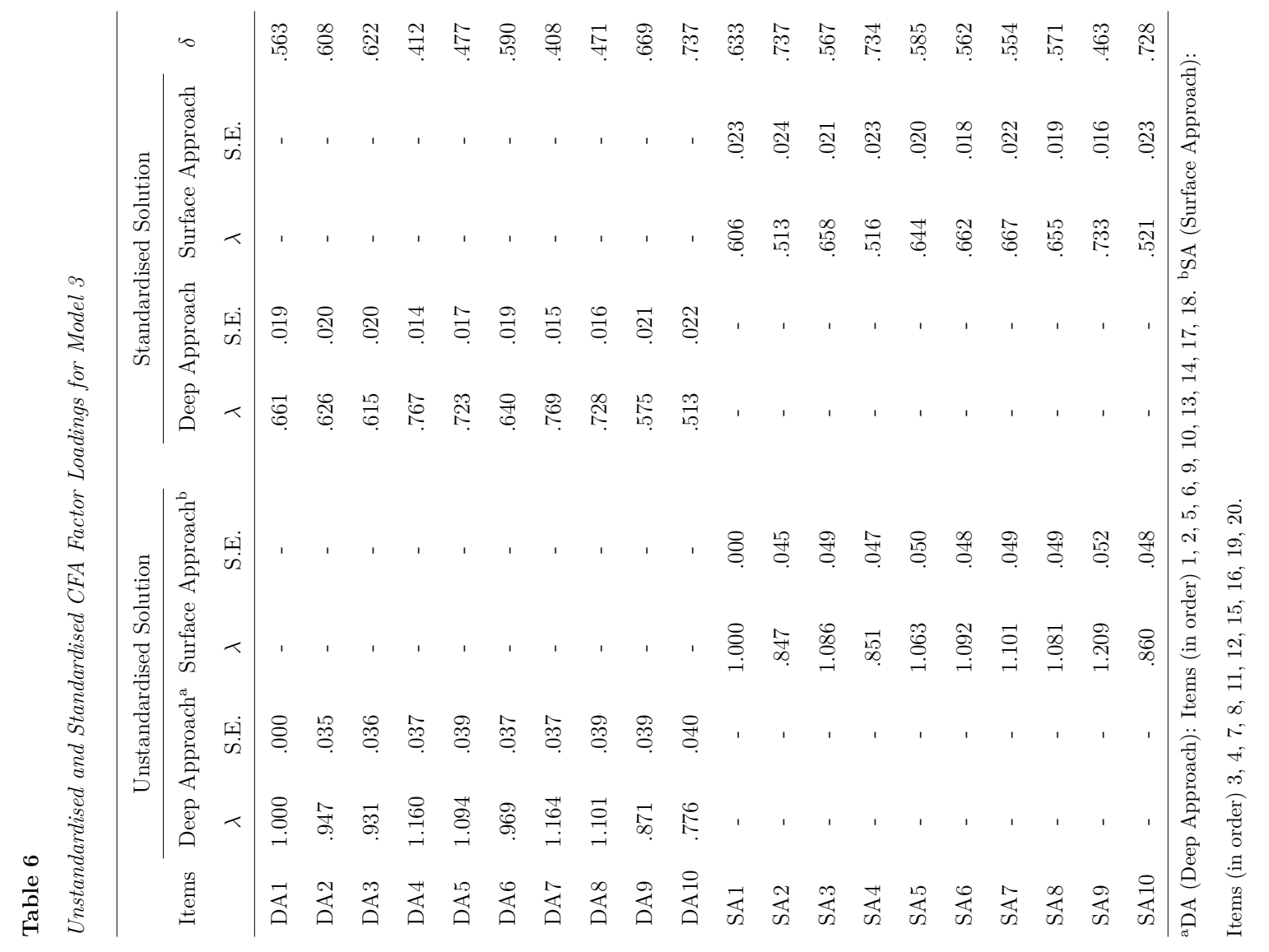


Table 7

ESEM Factor Loadings for Model 3

\begin{tabular}{|c|c|c|c|c|c|}
\hline \multirow{2}{*}{ Items } & \multicolumn{2}{|c|}{ Deep Approach } & \multicolumn{2}{|c|}{ Surface Approach } & \multirow{2}{*}{$\delta$} \\
\hline & $\lambda$ & S.E. & $\lambda$ & S.E. & \\
\hline 1 & .648 & .020 & -.061 & .022 & .569 \\
\hline 2 & .612 & .020 & -.064 & .021 & .615 \\
\hline 3 & -.039 & .024 & .599 & .024 & .635 \\
\hline 4 & -.087 & .023 & .486 & .024 & .748 \\
\hline 5 & .610 & .020 & .000 & .021 & .628 \\
\hline 6 & .771 & .013 & .027 & .017 & .409 \\
\hline 7 & -.190 & .021 & .626 & .022 & .551 \\
\hline 8 & .226 & .022 & .567 & .021 & .651 \\
\hline 9 & .714 & .017 & -.039 & .017 & .483 \\
\hline 10 & .655 & .018 & .043 & .019 & .574 \\
\hline 11 & .165 & .021 & .683 & .018 & .526 \\
\hline 12 & -.021 & .020 & .654 & .018 & .570 \\
\hline 13 & .751 & .016 & -.109 & .016 & .409 \\
\hline 14 & .733 & .016 & .048 & .017 & .466 \\
\hline 15 & .020 & .021 & .677 & .021 & .543 \\
\hline 16 & -.062 & .021 & .636 & .019 & .585 \\
\hline 17 & .596 & .020 & .107 & .021 & .645 \\
\hline 18 & .527 & .022 & .049 & .022 & .725 \\
\hline 19 & -.120 & .019 & .708 & .017 & .469 \\
\hline 20 & .116 & .023 & .549 & .022 & .696 \\
\hline
\end{tabular}




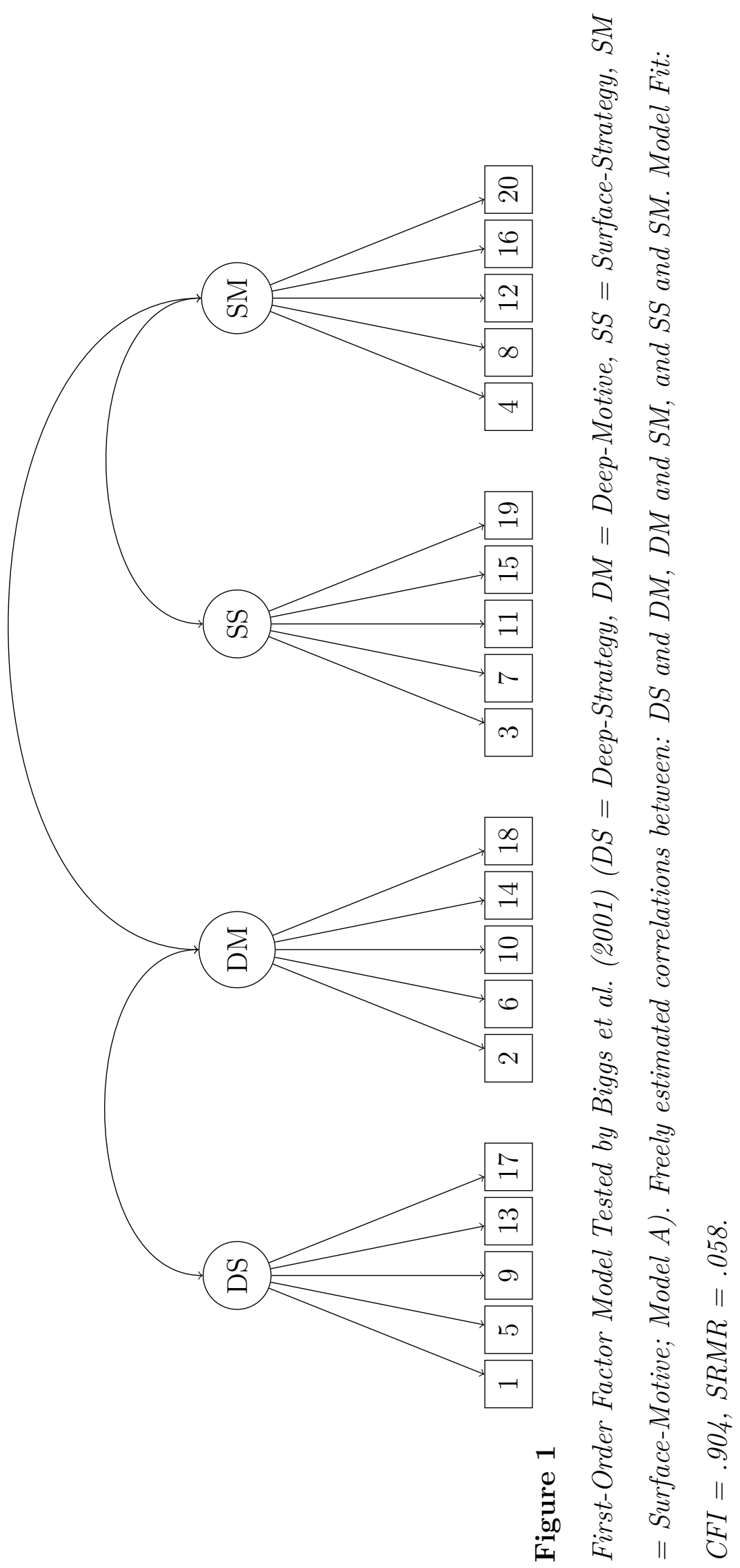




\section{Figure 2}

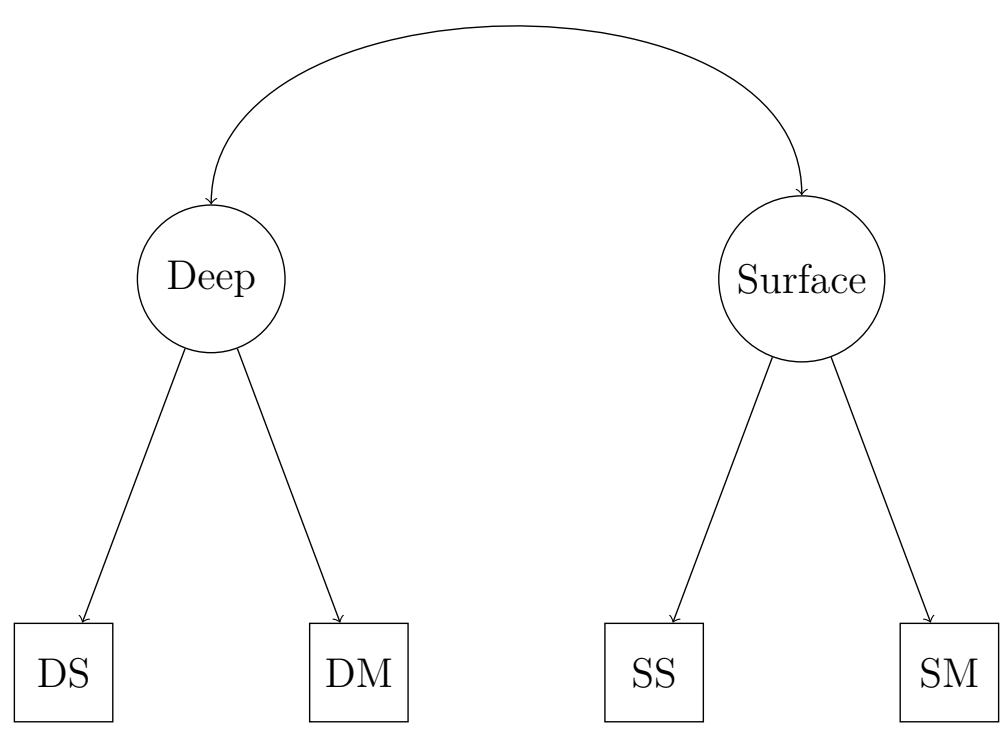

Higher-Order Factor Structure Tested by Biggs et al. (2001) using an Item Parcelling Approach $(D S=$ Deep-Strategy, DM = Deep-Motive, SS = Surface-Strategy, SM = Surface-Motive; Model B). Model Fit: CFI =.992, SRMR $=.015$. 

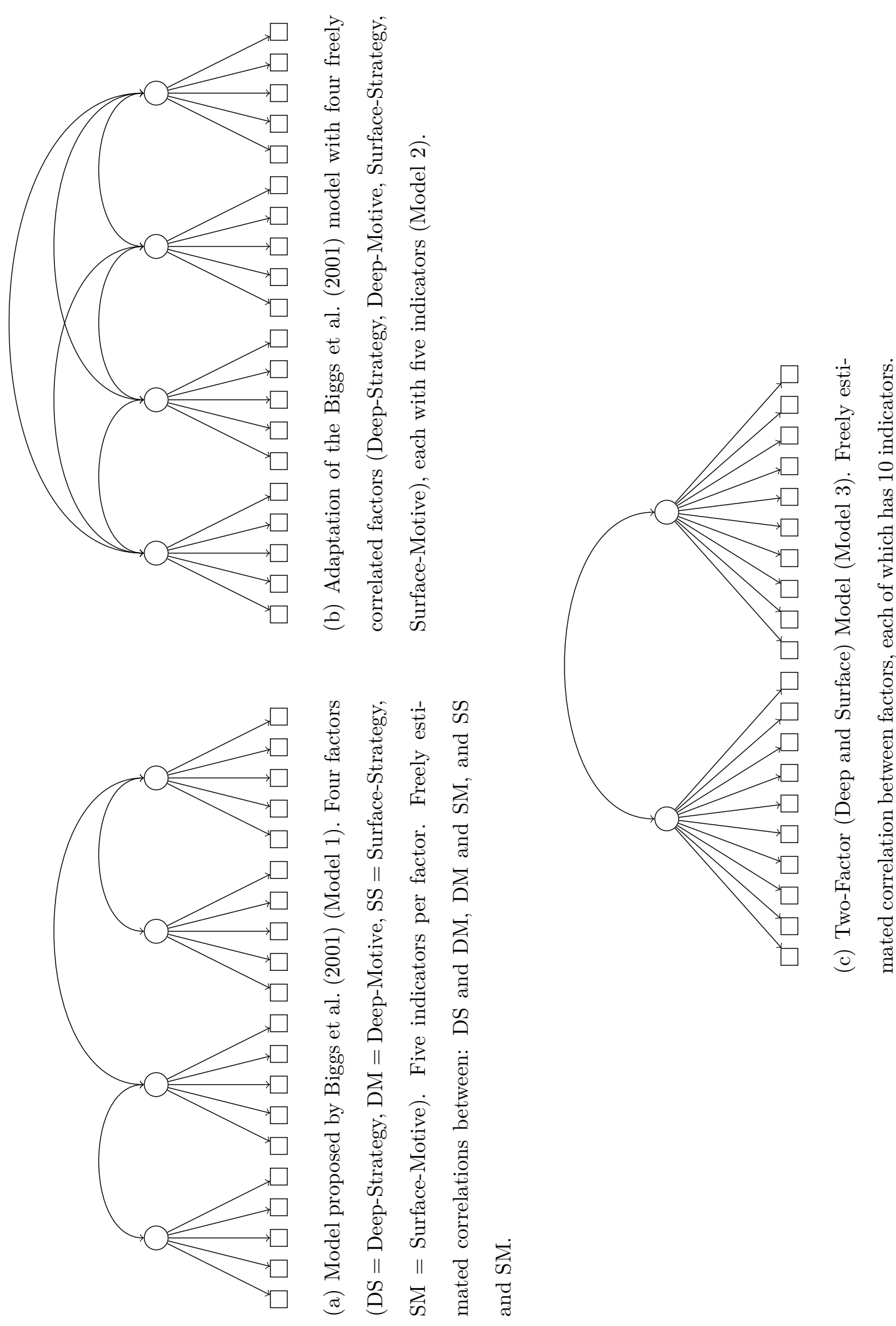

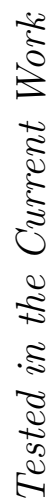

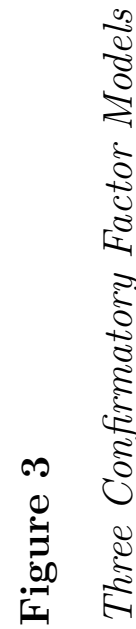


Appendix A

Age Distributions for Student Sample and Population
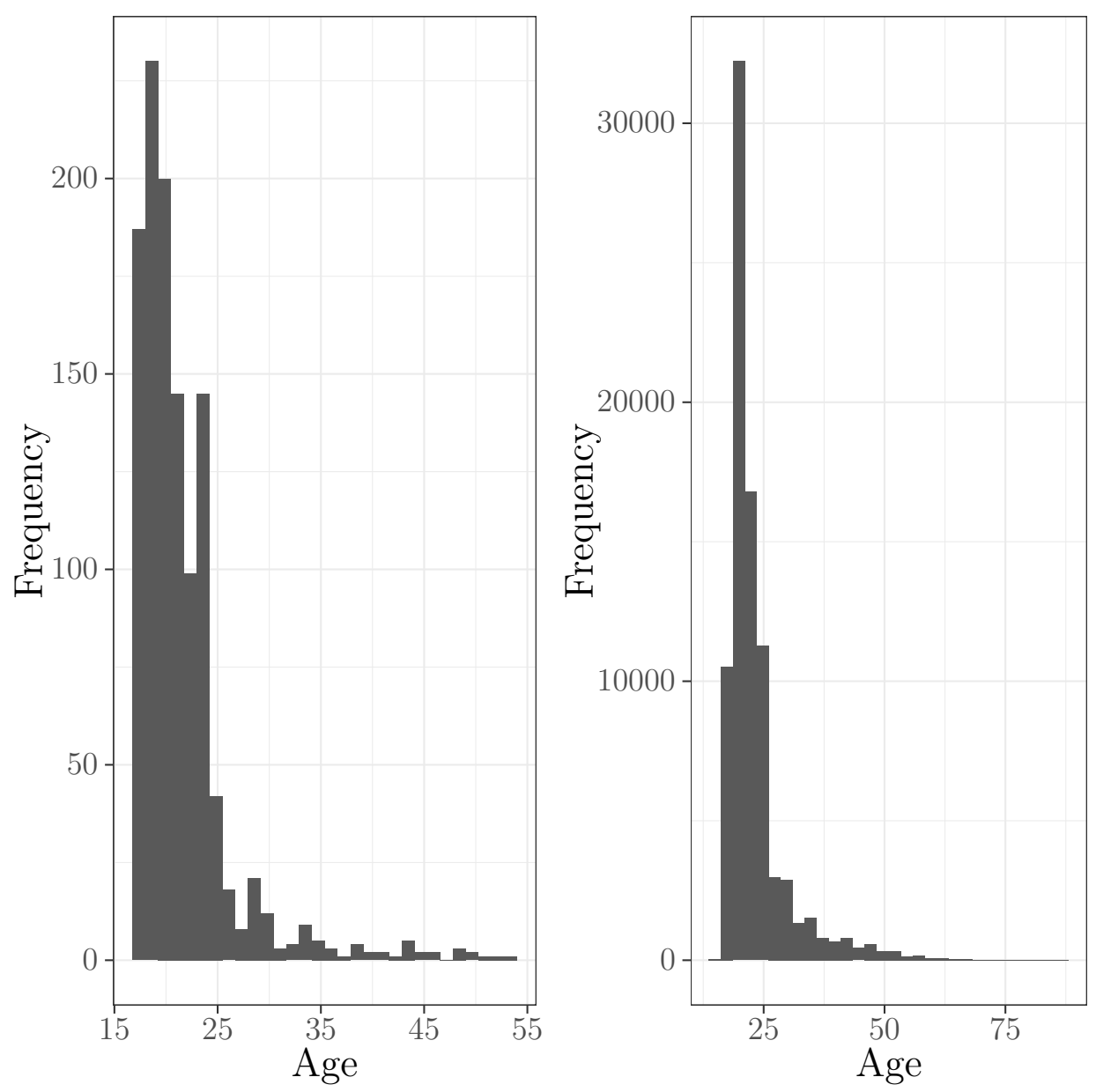

Figure A1

Age Distributions for the Student Sample (Left) and Student Population (Right) 


\section{Appendix B}

\section{Questionnaire Items and Response Distributions}

\section{Biggs et al. (2001) R-SPQ-2F}

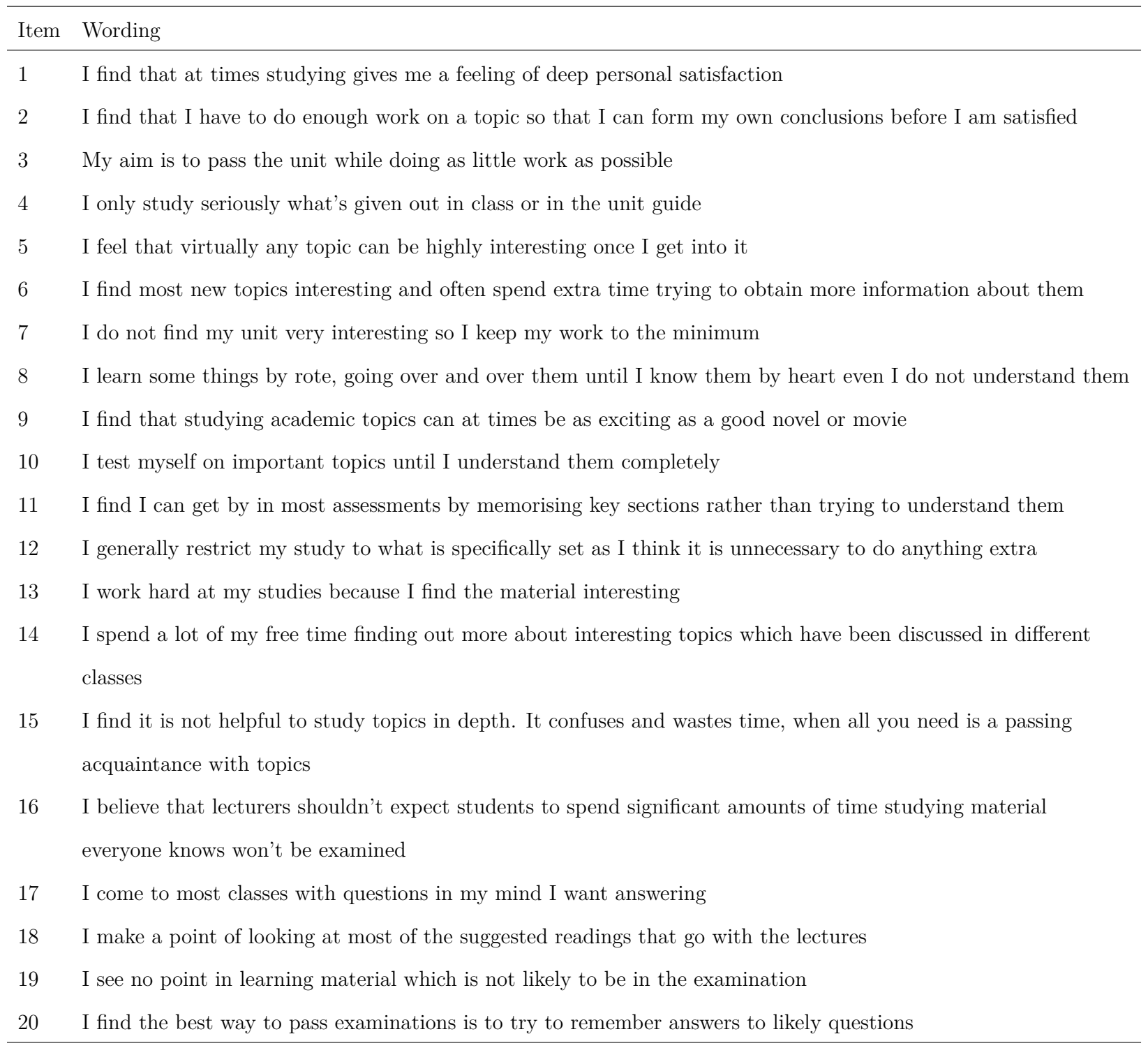

\section{Response Distributions for the R-SPQ-2F Items}



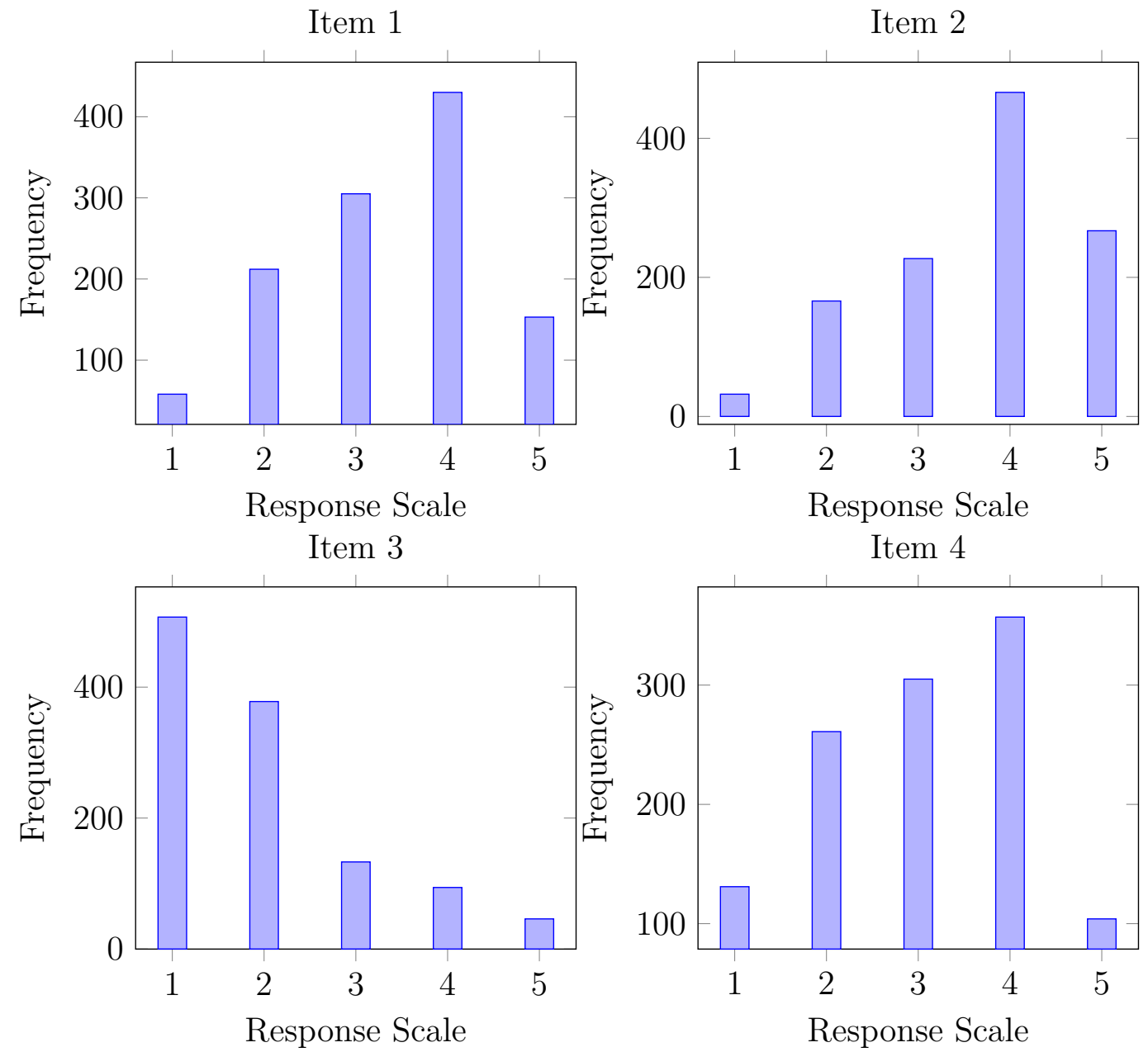

Item 4
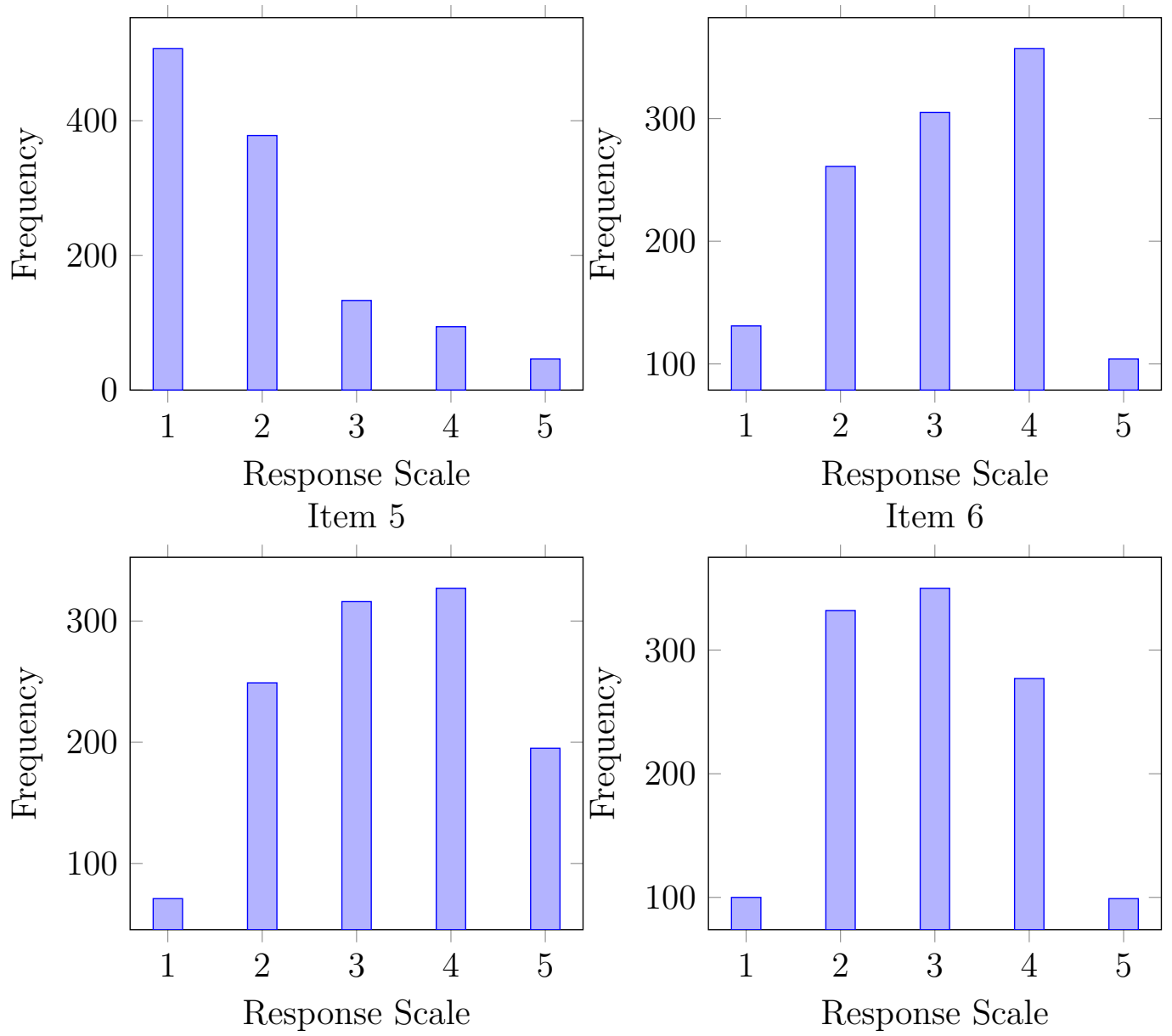

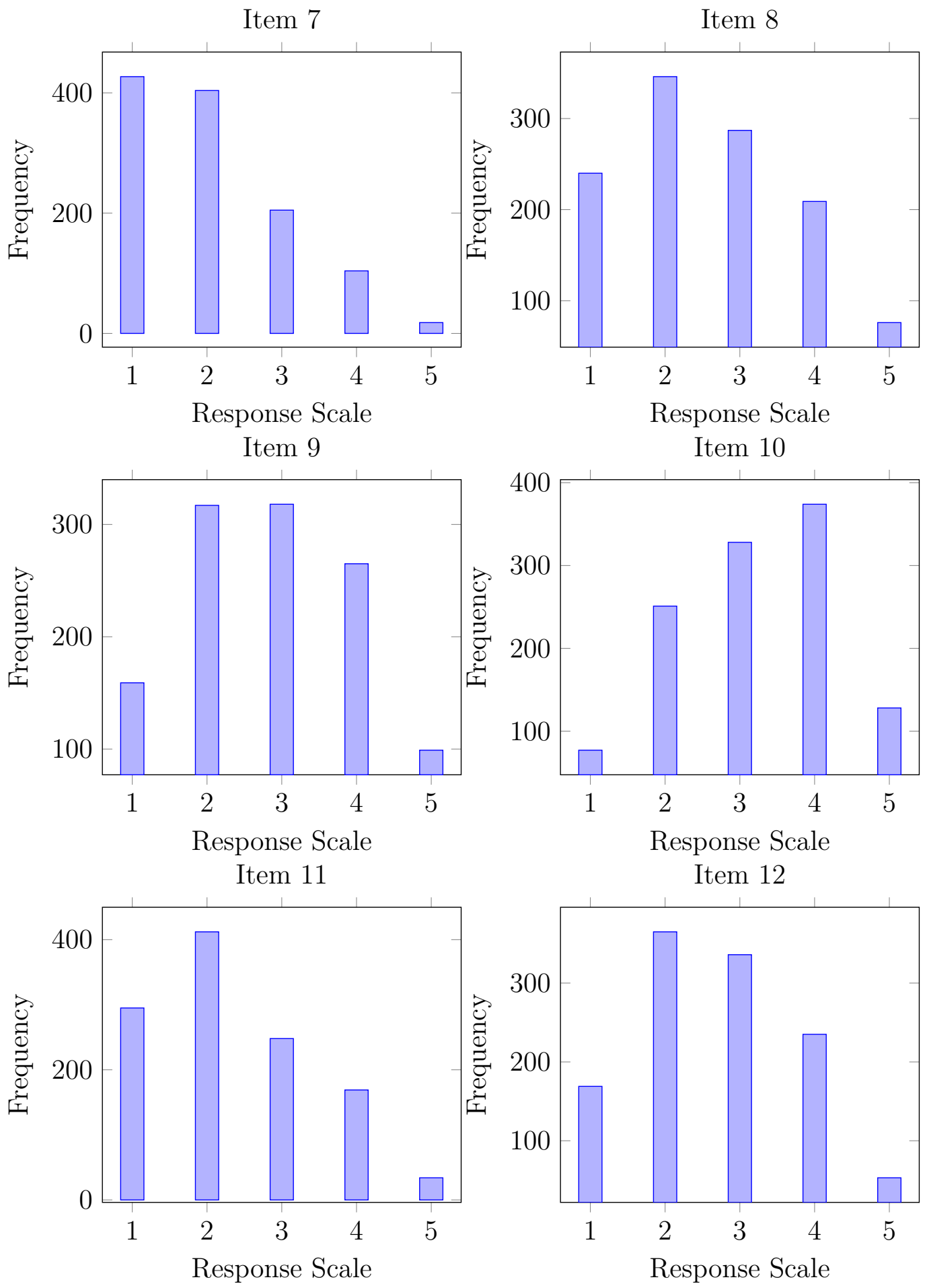

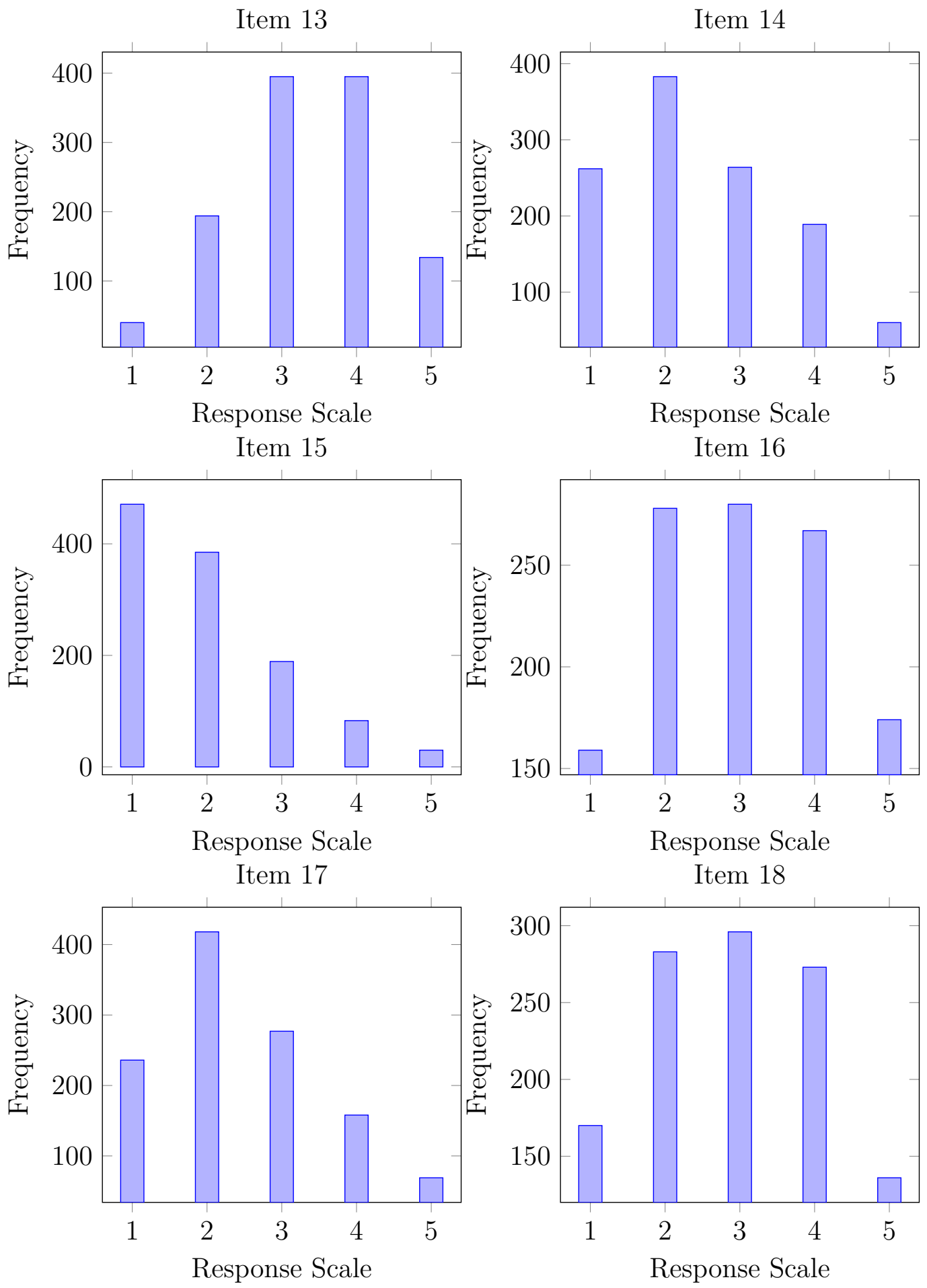
Item 19

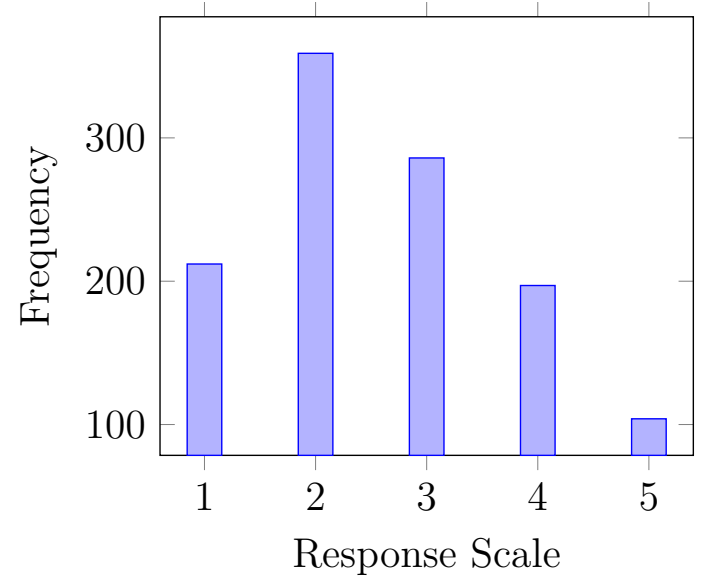

Item 20

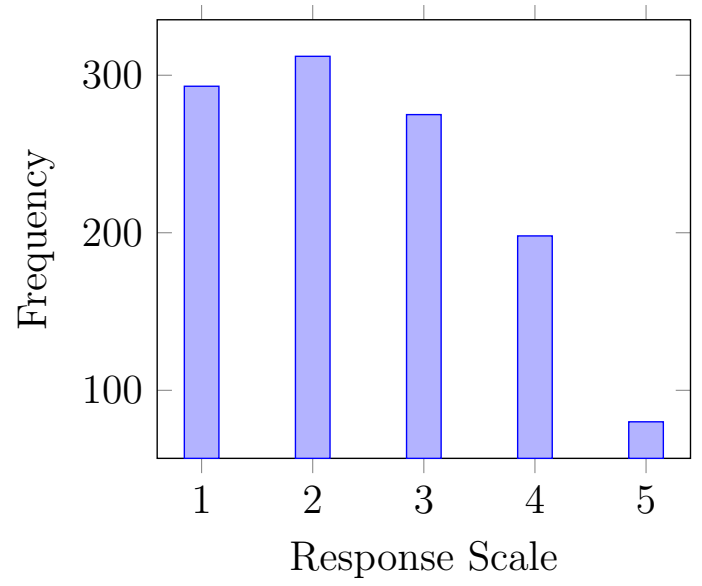




\section{Appendix C}

\section{Local Fit Measures: Model 2}

\section{Residual Correlations for Model 2 (ESEM)}

\begin{tabular}{|c|c|c|c|c|c|c|c|c|c|c|c|c|c|c|c|c|c|c|c|c|}
\hline & 1 & 2 & 3 & 4 & 5 & 6 & 7 & 8 & 9 & 10 & 11 & 12 & 13 & 14 & 15 & 16 & 17 & 18 & 19 & 20 \\
\hline 1 & - & & & & & & & & & & & & & & & & & & & \\
\hline 2 & .066 & - & & & & & & & & & & & & & & & & & & \\
\hline 3 & .036 & .053 & - & & & & & & & & & & & & & & & & & \\
\hline 4 & .019 & .031 & .111 & - & & & & & & & & & & & & & & & & \\
\hline 5 & .009 & .007 & .041 & .022 & - & & & & & & & & & & & & & & & \\
\hline 6 & -.018 & -.004 & .005 & -.025 & .078 & - & & & & & & & & & & & & & & \\
\hline 7 & .041 & .030 & .040 & .023 & -.024 & -.019 & - & & & & & & & & & & & & & \\
\hline 8 & .015 & .008 & .022 & -.006 & .004 & .038 & -.010 & - & & & & & & & & & & & & \\
\hline 9 & .009 & -.033 & .015 & -.002 & -.029 & -.003 & .031 & .002 & - & & & & & & & & & & & \\
\hline 10 & -.010 & .008 & -.043 & .009 & -.001 & -.004 & .062 & .026 & .007 & - & & & & & & & & & & \\
\hline 11 & -.004 & -.014 & .002 & -.016 & .025 & .014 & -.017 & .003 & .005 & -.012 & & & & & & & & & & \\
\hline 12 & -.007 & -.021 & .002 & .100 & .019 & .012 & -.007 & -.017 & .010 & -.039 & .036 & - & & & & & & & & \\
\hline 13 & -.012 & -.059 & -.035 & .028 & -.029 & -.036 & -.051 & -.051 & .042 & .001 & .007 & .057 & - & & & & & & & \\
\hline 14 & -.011 & .005 & -.015 & -.030 & -.047 & .015 & -.011 & -.015 & .002 & -.001 & .022 & -.023 & .024 & - & & & & & & \\
\hline 15 & 047 & .012 & -.009 & -.059 & -.007 & -.015 & .025 & .024 & -.017 & -.014 & -.014 & .006 & -.017 & .009 & - & & & & & \\
\hline 16 & -.079 & -.034 & -.062 & -.061 & -.033 & -.024 & -.034 & .004 & .026 & .016 & -.023 & -.030 & .058 & .014 & .013 & - & & & & \\
\hline 17 & -.005 & -.013 & -.002 & -.007 & -.025 & -.045 & .002 & -.023 & -.011 & .019 & -.032 & -.007 & .016 & -.008 & .021 & .020 & - & & & \\
\hline 18 & -.052 & .010 & -.037 & -.029 & -.036 & -.035 & -.031 & -.020 & -.034 & -.001 & -.041 & -.014 & .049 & -.020 & .005 & .036 & .103 & - & & \\
\hline 19 & -.028 & -.042 & -.077 & -.058 & -.024 & -.008 & -.028 & -.016 & -.042 & .014 & -.007 & -.039 & -.009 & .032 & .012 & .061 & .045 & .064 & - & \\
\hline 20 & -.020 & -.006 & -.003 & -.034 & -.011 & .021 & -.015 & -.003 & -.003 & -.025 & .023 & -.022 & .011 & .017 & -.037 & .012 & -.030 & .039 & .046 & - \\
\hline
\end{tabular}

\section{Areas of Localised Strain for Model 2 (ESEM)}

\begin{tabular}{cccccc}
\hline \multicolumn{2}{l}{ Items } & Residual Correlation & MI & EPC & SEPC \\
\hline 3 & 4 & .111 & 50.903 & .162 & .258 \\
4 & 12 & .100 & 64.774 & .148 & .238 \\
17 & 18 & .103 & 74.832 & .160 & .251 \\
\hline
\end{tabular}




\section{Appendix D}

\section{Local Fit Measures: Model 3}

\section{Residual Correlations for Model 3 (CFA)}

\begin{tabular}{|c|c|c|c|c|c|c|c|c|c|c|c|c|c|c|c|c|c|c|c|c|}
\hline & 1 & 2 & 3 & 4 & 5 & 6 & 7 & 8 & 9 & 10 & 11 & 12 & 13 & 14 & 15 & 16 & 17 & 18 & 19 & 20 \\
\hline 1 & - & & & & & & & & & & & & & & & & & & & \\
\hline 2 & .141 & - & & & & & & & & & & & & & & & & & & \\
\hline 3 & -.064 & -.050 & - & & & & & & & & & & & & & & & & & \\
\hline 4 & .004 & .019 & .079 & - & & & & & & & & & & & & & & & & \\
\hline 5 & .030 & .028 & .036 & .013 & - & & & & & & & & & & & & & & & \\
\hline 6 & -.063 & -.052 & .054 & -.085 & .084 & - & & & & & & & & & & & & & & \\
\hline 7 & -.177 & -.184 & .108 & -.015 & -.130 & -.081 & - & & & & & & & & & & & & & \\
\hline 8 & .135 & .114 & -.045 & -.059 & .079 & .160 & -.112 & - & & & & & & & & & & & & \\
\hline 9 & -.003 & -.047 & -.009 & -.072 & -.029 & .002 & -.105 & .115 & - & & & & & & & & & & & \\
\hline 10 & .036 & .051 & -.092 & -.006 & -.007 & -.039 & -.093 & .281 & -.001 & - & & & & & & & & & & \\
\hline 11 & .028 & .006 & -.028 & -.089 & .056 & .118 & -.066 & .226 & .074 & .172 & - & & & & & & & & & \\
\hline 12 & -.022 & -.038 & -.020 & .107 & .025 & .011 & -.038 & -.005 & -.022 & -.003 & .035 & - & & & & & & & & \\
\hline 13 & .010 & -.038 & -.129 & -.057 & -.025 & -.055 & -.270 & .051 & .036 & .013 & .036 & -.009 & - & & & & & & & \\
\hline 14 & -.093 & -.081 & .071 & -.109 & -.052 & .079 & -.024 & .111 & .014 & -.051 & .153 & -.025 & -.005 & - & & & & & & \\
\hline 15 & -.025 & -.066 & .046 & -.103 & .006 & .066 & .078 & .020 & -.011 & -.007 & .013 & -.009 & -.081 & .129 & - & & & & & \\
\hline 16 & -.048 & -.002 & -.101 & .015 & .005 & -.057 & -.092 & -.082 & -.022 & .027 & -.141 & -.014 & -.005 & -.053 & -.045 & - & & & & \\
\hline 17 & -.072 & -.084 & .082 & -.056 & -.049 & -.009 & .011 & .184 & -.009 & .015 & .177 & .034 & -.014 & .066 & .152 & -.026 & - & & & \\
\hline 18 & -.097 & -.038 & -.009 & -.090 & -.063 & -.020 & -.072 & .164 & -.036 & .010 & .129 & -.003 & .029 & .021 & .077 & -.030 & .160 & - & & \\
\hline 19 & -.065 & -.076 & -.105 & -.003 & -.037 & -.076 & -.062 & -.098 & -.135 & -.016 & -.108 & -.032 & -.133 & -.054 & -.032 & .152 & -.005 & -.010 & - & \\
\hline 20 & .010 & .017 & .000 & -.064 & .046 & .124 & -.029 & .079 & .058 & .082 & .101 & -.021 & .036 & .135 & -.010 & -.029 & .114 & .143 & .008 & - \\
\hline
\end{tabular}

\section{Areas of Localised Strain for Model 3 (CFA)}

\begin{tabular}{cccccc}
\hline \multicolumn{2}{c}{ Items } & Residual Correlation & MI & EPC & SEPC \\
\hline 1 & 2 & .141 & 62.226 & .191 & .326 \\
1 & 7 & -.177 & 39.251 & -.179 & -.317 \\
1 & 8 & .135 & 20.937 & .136 & .212 \\
2 & 7 & -.184 & 40.513 & -.187 & -.318 \\
2 & 8 & .114 & 15.096 & .115 & .172 \\
\hline
\end{tabular}

Continued on next page 
- continued from previous page

\begin{tabular}{|c|c|c|c|c|c|}
\hline \multicolumn{2}{|c|}{ Items } & \multirow{2}{*}{$\frac{\text { Residual Correlation }}{.108}$} & \multirow{2}{*}{$\frac{\mathrm{MI}}{29.283}$} & \multirow{2}{*}{$\begin{array}{l}\mathrm{EPC} \\
.152\end{array}$} & \multirow{2}{*}{$\frac{\text { SEPC }}{.253}$} \\
\hline 3 & 7 & & & & \\
\hline 3 & 13 & -.129 & 19.828 & -.131 & -.257 \\
\hline 3 & 16 & -.101 & 13.462 & -.123 & -.204 \\
\hline 3 & 19 & -.105 & 17.648 & -.136 & -.251 \\
\hline 4 & 12 & .107 & 28.080 & .141 & .220 \\
\hline 4 & 14 & -.109 & 14.859 & -.110 & -.187 \\
\hline 4 & 15 & -.103 & 14.219 & -.123 & -.192 \\
\hline 5 & 7 & -.130 & 20.280 & -.132 & -.222 \\
\hline 6 & 8 & .160 & 32.555 & .161 & .294 \\
\hline 6 & 11 & .118 & 16.081 & .119 & .243 \\
\hline 6 & 20 & .124 & 18.070 & .125 & .229 \\
\hline 7 & 8 & -.112 & 18.053 & -.134 & -.208 \\
\hline 7 & 9 & -.105 & 13.441 & -.107 & -.205 \\
\hline 7 & 13 & -.270 & 120.434 & -.277 & -.575 \\
\hline 8 & 9 & .115 & 16.362 & .116 & .197 \\
\hline 8 & 10 & .281 & 108.881 & .283 & .431 \\
\hline 8 & 11 & .226 & 186.216 & .322 & .492 \\
\hline 8 & 14 & .111 & 15.195 & .112 & .190 \\
\hline 8 & 17 & .184 & 43.491 & .185 & .264 \\
\hline 8 & 18 & .164 & 30.085 & .164 & .224 \\
\hline 9 & 19 & -.135 & 23.851 & -.137 & -.292 \\
\hline 10 & 11 & .172 & 34.945 & .174 & .297 \\
\hline 11 & 14 & .153 & 28.953 & .155 & .296 \\
\hline 11 & 16 & -.141 & 30.964 & -.176 & -.305 \\
\hline
\end{tabular}

Continued on next page 
- continued from previous page

\begin{tabular}{cccccc}
\hline \multicolumn{2}{l}{ Items } & Residual Correlation & MI & EPC & SEPC \\
\hline 11 & 17 & .177 & 40.210 & .179 & .286 \\
11 & 18 & .129 & 20.284 & .130 & .198 \\
11 & 19 & -.108 & 22.388 & -.145 & -.278 \\
11 & 20 & .101 & 22.224 & .130 & .199 \\
13 & 19 & -.133 & 24.152 & -.136 & -.313 \\
14 & 15 & .129 & 20.217 & .131 & .256 \\
14 & 20 & .135 & 23.203 & .136 & .233 \\
15 & 17 & .152 & 25.987 & .154 & .253 \\
16 & 19 & .152 & 137.765 & .284 & .552 \\
17 & 18 & .160 & 59.159 & .193 & .275 \\
17 & 20 & .114 & 15.203 & .114 & .164 \\
18 & 20 & .143 & 22.925 & .144 & .196 \\
\hline \hline
\end{tabular}




\section{Residual Correlations for Model 3 (ESEM)}

\begin{tabular}{|c|c|c|c|c|c|c|c|c|c|c|c|c|c|c|c|c|c|c|c|c|}
\hline & 1 & 2 & 3 & 4 & 5 & 6 & 7 & 8 & 9 & 10 & 11 & 12 & 13 & 14 & 15 & 16 & 17 & 18 & 19 & 20 \\
\hline 1 & - & & & & & & & & & & & & & & & & & & & \\
\hline 2 & .147 & - & & & & & & & & & & & & & & & & & & \\
\hline 3 & -.010 & .005 & - & & & & & & & & & & & & & & & & & \\
\hline 4 & .082 & .096 & .089 & - & & & & & & & & & & & & & & & & \\
\hline 5 & .038 & .036 & .053 & .060 & - & & & & & & & & & & & & & & & \\
\hline 6 & -.057 & -.045 & .059 & -.040 & .087 & - & & & & & & & & & & & & & & \\
\hline 7 & -.025 & -.037 & .112 & -.011 & -.023 & .037 & - & & & & & & & & & & & & & \\
\hline 8 & .018 & .007 & -.053 & -.045 & -.062 & -.033 & -.081 & - & & & & & & & & & & & & \\
\hline 9 & .003 & -.040 & .033 & .001 & -.022 & .006 & .045 & -.029 & - & & & & & & & & & & & \\
\hline 10 & .037 & .053 & -.099 & .024 & -.010 & -.049 & -.004 & .107 & -.004 & - & & & & & & & & & & \\
\hline 11 & -.044 & -.058 & -.034 & -.075 & -.049 & -.034 & -.041 & .156 & -.024 & .032 & - & & & & & & & & & \\
\hline 12 & .023 & .008 & -.015 & .121 & .030 & .000 & -.028 & -.017 & .009 & -.024 & .027 & - & & & & & & & & \\
\hline 13 & .014 & -.033 & -.043 & .053 & -.015 & -.046 & -.069 & -.064 & .042 & .015 & $\begin{array}{l}-.022 \\
\end{array}$ & .068 & - & & & & & & & \\
\hline 14 & -.086 & -.073 & .063 & -.076 & -.050 & .075 & .075 & -.084 & .018 & -.062 & -.005 & -.049 & .005 & - & & & & & & \\
\hline 15 & -.005 & -.043 & .044 & -.092 & -.013 & .024 & .087 & -.010 & -.008 & -.055 & -.012 & -.009 & -.031 & .074 & - & & & & & \\
\hline 16 & .021 & .068 & -.093 & .029 & .034 & -.037 & -.085 & -.081 & .037 & .032 & -.137 & -.002 & .101 & -.047 & -.040 & - & & & & \\
\hline 17 & -.069 & -.080 & .035 & -.062 & -.053 & -.021 & .048 & -.011 & -.010 & -.003 & .004 & -.029 & -.006 & .051 & .063 & -.064 & - & & & \\
\hline 18 & -.096 & -.036 & -.023 & -.073 & -.066 & -.029 & -.010 & .016 & -.038 & -.003 & .006 & -.030 & .032 & .011 & .028 & -.035 & .144 & - & & \\
\hline 19 & .046 & .033 & -.098 & .008 & .027 & -.015 & -.064 & -.086 & -.033 & .023 & -.097 & -.021 & .023 & -.011 & -.026 & .164 & -.018 & .011 & - & \\
\hline 20 & -.037 & -.025 & -.004 & -.053 & -.029 & .015 & -.011 & .027 & -.009 & -.020 & .058 & -.027 & .002 & .020 & -.028 & -.026 & -.016 & .053 & .017 & - \\
\hline
\end{tabular}


Areas of Localised Strain for Model 3 (ESEM)

\begin{tabular}{cccccc}
\hline Items & Residual Correlation & MI & EPC & SEPC \\
\hline 1 & 2 & .147 & 123.885 & .196 & .332 \\
3 & 7 & .112 & 57.996 & .156 & .263 \\
4 & 12 & .121 & 65.949 & .158 & 242 \\
8 & 10 & .107 & 36.658 & .134 & .220 \\
8 & 11 & .156 & 184.341 & .249 & .425 \\
11 & 16 & -.137 & 55.602 & -.175 & -.315 \\
13 & 16 & .101 & 28.853 & .128 & .261 \\
16 & 19 & .164 & 288.489 & .296 & .566 \\
17 & 18 & .144 & 90.215 & .176 & .258 \\
\hline
\end{tabular}

